\title{
Crafting the Future Story Together
}

\begin{abstract}
In this chapter, we discuss how after the Collaborative Story Craft intervention, practitioners can continue crafting and building their future stories together at work. Work engagement requests material resources and support, a sense of psychological and physical safety to be oneself, and meaningful rewards and recognition.

Although narratives and stories, on the surface, may seem fixed, raising awareness of the stories through Collaborative Storytelling provides an opportunity to create and maintain an organisational culture which strives for inclusion through responsible and sustainable practices of change.
\end{abstract}

Keywords Employee engagement $\bullet$ Metaphoric fields $\bullet$ Political and social activism $\bullet$ Sustainability $\bullet$ Story Craftivism

Life is a journey to be experienced, not a problem to be solved -Winnie the Pooh, A.A. Milne

The presence of a Story Mediator is not a permanent fixture, just like Michael White's metaphor of scaffolding when working with stories in therapeutic practice. With this in mind, each stage of Collaborative Story Craft gives potential tools and skills to continue building narratives at

(C) The Author(s) 2022

T. Cleland Silva, P. de Tarso Fonseca Silva, Making Sense of Work

Through Collaborative Storytelling, https://doi.org/10.1007/978-3-030-89446-7_6 
work in various situations and times by the actors within the community of practice. Like Paulo Freire (1970), who empowered rural farmers with literacy skills needed for their life circumstances, Collaborative Story Craft strives to provide skills for future story exchange independently.

To continue building narratives towards sustainable and inclusive change requests a work as craft mindset to stay open, curious, and critical of the stories and metaphors exchanged at the workplace. This also means taking a moral stance and responsibility of what and how stories are exchanged and their material consequences on the work and individual well-being.

In 2017, a storyteller in a Collaborative Story Craft workshop mentioned to her colleagues that she was frustrated and tired of focusing on short-term production deadlines and not discussing the bigger vision behind the work's deeper purpose. To tell this story, she got up and drew a brick wall on a white board and described herself as a stick figure with an arrow starting from her chest. The arrow barely made it over the wall, and yet the other side of the wall is what she yearned for. She described this feeling as wanting something more from her work, to feel that her contribution mattered.

Similarly, work psychologist William Kahn (1990), inspired by the stories of summer camp counsellors, wrote that employees feel engaged at work when they have access and support to material resources, they feel physically and emotionally safe to be oneself, and the work is meaningful through recognition and rewards. In other words, their effort and contribution matters to the community of practice, and when it does not, they physically and psychologically withdraw from their working role.

Most often, a fast pace of production that is driven by short-term deadlines and profit-oriented goals leads to what André Spicer calls in his book "Business Bullshit" a "Sisyphus's to-do list” (2018, p. 69).

Sisyphus's story is similar to "hitting a wall" with meaningless work. In his case, Sisyphus was punished by the Greek God Hades for misdeeds in life by being condemned to the eternal task of rolling a large stone to the top of a hill, from which it always rolled down again. 
Being in a constant state of rushing to get work done and not reflecting on the deeper purpose can lead to disengagement, emotional tax, burnout, and people leaving the workplace all together. It can also create a sense of "hopelessness" (see Cook 2007 on psychiatric nurses) or not seeing beyond the wall as to why the work matters.

\section{STORY CRaftivism}

As practitioners, when we talk about storytelling, it is common for people to signify story work as a "hobby" or project, their sensemaking of storytelling as something "trendy," and they treat it like a "buzzword."

Needless to say, there is nothing novel about telling stories, but perhaps a motive to strategically use stories as a means to a commodified, capitalist end (Boje 1995). Storytelling for inauthentic purposes is like constructing craft products and services as "handmade" for the sole purpose of appealing to conscious consumerism (Bell et al. 2019). Inauthentic storytelling and craft become more an instrument at the expense of connection and deeper collective meaning.

Nevertheless, there is hope. In our field of work, practitioners, who are passionate about stories and critical of dominant narratives, are growing as a community and their practices are increasingly more well defined. In this growing community, there is a sense of responsibility expressed through narratives of sustainable practices towards a bigger, collective purpose. This sense of responsibility is a common theme, which we identify in our peers and in ourselves.

The nuances of storytelling practices, which resonate with us, go beyond "business as usual" (Scheyvens et al. 2016), as they deal with and aspire for sustainable and inclusive change in working life and other global systems. These ways of working with stories can be described as social activism or what we call "Story Craftivism."

Story Craftivism is Collaborative Storytelling with a work as craft mindset. Story Craftivism is a movement that challenges dominant narratives and scripts to promote social and sustainable change through the exchange of authentic stories.

Like most forms of social activism, conscious raising and resistance derives from times of crisis, driven by meaningful motivations for individual and collective change. 
As an intervention method, Collaborative Story Craft was built on four questions we asked ourselves in relation to equity and inclusion (Cleland Silva 2021):

1. What if the dominant collective story of a group did not resonate with all the members?

2. What if this disconnect was the cause (not the symptom) of tensions in the group?

3. Could we create a method that united the members under a common story or metaphor?

4. And could this common story lead to multiple voices and possible inclusion in the collective story?

The questions we posed many years ago came from our desire to make sense of our lived experiences as "foreigners" working and living in a Nordic welfare state. Both of us are socially constructed as "highly skilled immigrants" based on our nationalities and acquired education, which affects how we navigate and experience the local system of governance influenced by our social and global rank. For instance, local narratives constructed about "foreigners" impacted how we navigated and made sense of our physical and social lives as well as our economic opportunities to acquire either education skills and/or work while raising a family. At this time, our sense of community held many members who also identified as "foreigners" and yet each person had different material experiences based on how their social identities were constructed by the local narratives (see Cleland Silva 2019, pp. 80-81). We can only explain this "foreigner" sensemaking of embodied lived experiences as stepping in and out of dominant and peripheral worlds and, at times, this discomfort of the unknown or being perceived as the unknown could feel like purgatory. Yet, through these circumstances, we saw humanity in others, ourselves, and in the arbitrariness of seemingly fixed narratives and practices. In many respects, honouring our stories and others helped us get through the hard times and craft stories that are more resilient, emphatic, and accountable.

The strangers in your midst shall be to you as the native born, for you know the stranger's heart, for you were strangers in the land of Egypt. Exodus 23:9 
As a metaphoric field, purgatory can be a state of mind that is manifested in different scales in different social worlds, where power dynamics can stir one's faith subjectively and unpredictably. People who are dependent on inclusion find themselves in a situation where being included becomes a condition for having access to resources and opportunities. Those people are likely the same ones whose stories are silenced or do not relate to the stories of the dominant group.

Expanding on the meaning of being "foreigners," we consider the opposite sides of power. One side controls what stories should be told, while the other side expects to be "included" in a story where they are seen and heard. Both sides cannot exist alone, and yet there are hidden conditions and responsibilities associated with the equilibrium of stories.

"Foreigner" to us is anyone who seeks to be part of something bigger but is still uniquely different. The dominant story at work is one of the social worlds where "foreignness" is at play, as our embodied stories are either included or dismissed. That description is a reminder that anyone could be a foreigner, standing at the peripheral borders of a bigger powerful story.

In order to craft a future story together, we need to understand our position of power without neglecting our responsibilities. This begs the questions: What is your type of "foreignness"? Where do you position yourself? Do you often feel like a foreigner? If so, can you enter the bigger story? If you see yourself in the bigger story, how do you see the walls? What do you see through the windows? Can you open any doors?

\section{Conclusions}

In Chap. 2, we introduced the Social Worlds of Snakes and Ladders to illustrate how power is evasive and interwoven in systems of narratives where dominant, social narratives are context-specific, relational, and most often, considered fixed.

In this chapter, through the Story Craftivist lens, we described our own experiences as "foreigners," and how, through these experiences, we navigated different circumstances which were influenced by our perceived social ranks in context.

Entering the unknown and being perceived as the unknown strengthened our sense of personal power. It also cultivated our self-awareness of the impact of dominant narratives on the material and social worlds of those constructed. 
When personal power is activated, it can also be synchronised with others to question well-established stories, not with the intention of replacing the stories of those in power, but to consider an exchange of stories from different positions and lived experiences. When this approach is incorporated in organisational change, Collaborative Storytelling Activity will no longer be a parallel activity to the work, but rather integrated into the activity system through ethical and sustainable practices.

\section{REFERENCES}

Bell, Emma, Gianluigi Mangia, Scott Taylor, and Maria Laura Toraldo, eds. 2019. The organization of craft work: Identities, meanings, and materiality. New York: Routledge.

Boje, D.M. 1995. Stories of the storytelling organization: A postmodern analysis of Disney as "Tamara-Land". Academy of Management Journal 38 (4): 997-1035.

Cleland Silva, Tricia. 2019. Translational management and globalised workers: Nurses beyond human resources. New York: Routledge.

- 2021. Meaningful and inclusive workplaces through story. TedxMetropoliaUniversity, April 22. https://www.ted.com/talks/tricia_cleland_ silva_meaningful_and_inclusive_workplaces_through_story.

Cook, Gina M. 2007. Burnout and Hopelessness among nurses working on Midwest Community psychiatric hospital units. Theses and Dissertations: 3171. Freire, Paulo. 1970. Pedagogy of the oppressed. New York: Continuum.

Kahn, William A. 1990. Psychological conditions of personal engagement and disengagement at work. Academy of Management Journal 33 (4): 692-724.

Scheyvens, Regina, Glenn Banks, and Emma Hughes. 2016. The private sector and the SDGs: The need to move beyond 'business as usual'. Sustainable Development 24 (6): 371-382.

Spicer, André. 2018. Business bullshit. New York: Routledge. 
Open Access This chapter is licensed under the terms of the Creative Commons Attribution 4.0 International License (http://creativecommons.org/licenses/ by $/ 4.0 /)$, which permits use, sharing, adaptation, distribution and reproduction in any medium or format, as long as you give appropriate credit to the original author(s) and the source, provide a link to the Creative Commons licence and indicate if changes were made.

The images or other third party material in this chapter are included in the chapter's Creative Commons licence, unless indicated otherwise in a credit line to the material. If material is not included in the chapter's Creative Commons licence and your intended use is not permitted by statutory regulation or exceeds the permitted use, you will need to obtain permission directly from the copyright holder. 